\title{
Implementing Quality Improvements in Public Transport
}

\author{
Margareta Friman, Karlstad University, Sweden
}

\begin{abstract}
This study addresses two questions: (1) What effect does quality improvement have on satisfaction with public transport services? (2) What effect does quality improvement have on passengers' perceived frequency of negative critical incidents? A representative sample was used of people 16 to 75 years old in the 13 regions in Sweden that were conducting quality improvements in public transport. Data were collected before and after implementation $(n=2797)$. The before and after samples consisted of independent groups of respondents. The response rate was 54 percent. The main conclusion of the study is that the satisfaction people experience when using public transport services is influenced by quality improvements only to a limited extent. Furthermore, the effect was directionally opposite in that respondents reported less satisfaction and higher frequencies of negative critical incidents after the quality improvements had been implemented.
\end{abstract}

\section{Introduction}

Recent years have witnessed an emphasis on delivering high-quality services to customers using public transport (e.g., Cunningham, Young, and Kroeter 1995; leda et al. 2000). Empirical evidence exists from other services that support the link between quality improvements and customer satisfaction (e.g., Bolton and Drew 
Journal of Public Transportation, Vol. 7, No. 4, 2004

1991; Nilsson, Johnson, and Gustafsson 2001; Simester et al. 2000). However, we know relatively little about the consequences of quality improvement programs in public transport services. An important question to ask is: Do quality improvements influence satisfaction? Thus, an aim of the present study is to examine the effects of different quality improvements among users of public transport services.

\section{Consumer Satisfaction}

A substantial amount of research in recent years has dealt with consumer satisfaction (e.g., Cadotte, Woodruff, and Jenkins 1987; Churchill and Surprenant 1982; Fornell 1992; Oliver 1980, 1997; Oliver and Swan 1989; Tse and Wilton 1988; Westbrook 1987). One approach in this research emphasizes transaction-specific or encounter satisfaction; that is, satisfaction with single transactions or encounters with a product or service (e.g., Oliver 1980; Oliver and DeSarbo 1988). Another approach focuses on cumulative satisfaction (e.g., Bolton and Drew 1991; Fornell 1992; Westbrook and Oliver 1991). In the latter approach it is assumed that satisfaction is determined by satisfying or dissatisfying encounters with a product or service over time. In both approaches satisfaction is either defined as overall satisfaction or broken down into satisfaction with performance attributes (Anderson and Sullivan 1993; Cronin and Taylor 1992; Gotleib, Grewal, and Brown 1994).

\section{The Role of Critical Incidents in Satisfaction Formation}

A critical incident is an encounter that is particularly satisfying or dissatisfying (e.g., Bitner, Booms, and Tetreault 1990). Its occurrence is assumed to have a significant impact on satisfaction. In public transport services, negative critical incidents may have the highest impacts. Examples are delay in the service, lack of information, misinformation, or rude employees/staff. In contrast to being customers of services that focus more on positive feelings (e.g., restaurants or entertainment outlets), avoiding dissatisfaction is likely to be the passengers' goal when using public transport services. An important question to ask is: What influences do negative critical incidents have on satisfaction?

One possibility proposed and tested by Friman, Edvardsson, and Gärling (2000) is that the frequency of remembered negative critical incidents is the source of attribute-specific cumulative satisfaction. This, in turn, has a direct effect on overall cumulative satisfaction. An example is that the remembered frequency of delays is related to attribute-specific satisfaction as a certain degree of unreliability of the service, which has a negative effect on a passenger's overall cumulative satisfaction with the service. 
In an experimental study, Friman and Gärling (2001) further examined the influences on satisfaction of different frequencies and types of negative critical incidents. As hypothesized, attribute-specific cumulative satisfaction was found to be related to the frequency of negative critical incidents, and overall satisfaction to attribute-specific satisfaction. The frequency of different negative critical incidents had about equally great effect on satisfaction with attributes corresponding to specific types of negative critical incidents. However, the effect on overall satisfaction of these frequencies varied. For instance, those related to rude treatment by employees, unreliability of service, and lack of or misleading information had greater effects than frequencies related to poor vehicle design. This finding can partly be explained by differences in affective reactions caused by different incidents (Friman 2001).

If service performance is low (e.g., slow performance, long delays, no direct line), passengers are likely to be less satisfied over time. Conversely, high service performance is assumed to increase satisfaction with the service. One possible explanation is that low service performance results in many negative critical incidents. Consistent with previous results (Friman, Edvardsson, and Gärling 2001), this will lead to low overall and attribute-specific cumulative satisfaction. An implication of this logic is that quality improvements should increase overall satisfaction and decrease the total frequency of negative critical incidents.

Friman, Edvardsson, and Gärling (2001) found that different negative critical incidents had selective effects on corresponding attributes. By including different quality improvements in this study, the relationship between type of improvement, type of negative critical incident, and attribute-specific satisfaction were possible to explore.

\section{Method}

\section{Overview and Samples}

The general research strategy was to measure perceived frequency of negative critical incidents and satisfaction in an initial data collection (Time 1, before quality improvements had been initiated) and in a second data collection (Time 2, when improvements had been completed). After contacting all transport authorities in Sweden ( 25 in total), only public transport companies that had budgeted and planned for quality improvements during the forthcoming year were selected to participate. As a result, 18 quality improvements implemented by 13 companies 
responsible for local bus service in just as many regions were included in this study. Specific improvements were in information systems (4), vehicle standards (7), increased number of departures (3), and construction of travel centers (4).

Sample 1. A random sample of 2,600 respondents was selected consisting of people between 16 and 75 years old from the 13 regions. (See Table 1 for population and sample sizes in each region.) Questionnaires were mailed to each respondent's home with a reply-paid envelope. To increase the response rate, the addressees were told that the first 100 to answer would receive a lottery ticket. Two reminders were sent out, the last one with a new copy of the questionnaire.

After three months, 1,250 usable questionnaires had been received corresponding to a response rate of 48 percent, of which 40 percent were men and 60 percent women. The mean age was 45.0 years (SD $=19.1$ years). Twenty-six percent reported that they used public transport on average more than once a week; 5 percent reported that they had no possibility to choose other means of travel than bus.

Table 1. Population, Sample Sizes, and Response Rates of the 13 Regions

\begin{tabular}{lcccc}
\hline Region & Population & $\begin{array}{c}\text { Sample } \\
\text { Size }\end{array}$ & T 1 & T 2 \\
\hline Karlstad & 80,958 & 200 & 93 & 123 \\
Halmstad & 86,504 & 200 & 86 & 114 \\
Kalmar & 60,026 & 200 & 91 & 130 \\
Ljungby & 26,965 & 200 & 79 & 110 \\
Gällivare & 19,408 & 200 & 83 & 107 \\
Piteå & 40,519 & 200 & 80 & 112 \\
Arjeplog & 3,297 & 200 & 91 & 107 \\
Luleå & 72,118 & 200 & 101 & 107 \\
Jönköping & 18,509 & 200 & 91 & 115 \\
Söderhamn & 27,278 & 200 & 97 & 107 \\
Hudiksvall & 37,053 & 200 & 92 & 119 \\
Vaxholm & 9,612 & 200 & 102 & 124 \\
Örebro & 125,461 & 200 & 164 & 172 \\
\hline Total & & 2,600 & 1,250 & 1,547 \\
\hline
\end{tabular}

\footnotetext{
${ }^{1}$ Response rate Time 1, sample 1

${ }^{2}$ Response rate Time 2, sample 2
} 
Sample 2. Another random sample of 2,600 respondents living in the same regions (see Table 1) was selected after the improvements had been completed. (The post-test measures were collected approximately one year after completion of the improvements.) The sample consisted of people between 16 and 75 years old. Questionnaires were mailed to each respondent's home with a reply-paid envelope. To increase the response rate, all respondents received a lottery ticket. Two reminders were sent out, the last one with a new copy of the questionnaire.

After three months, 1,547 usable questionnaires had been received corresponding to a response rate of 60 percent, of which 37 percent were men and 61 percent women. The mean age was 44.5 years (SD $=16.2$ years). Twenty-five percent reported that they used public transport on average more than once a week; 4 percent reported that they had no option to choose other means of travel than bus.

Nonusers in sample 1 (202) and sample 2 (286) were removed from further analyses.

\section{Questionnaire}

The questionnaire consisted of three modules and concerned experiences with public transport services. In module $A$, respondents were asked to rate their cumulative overall and attribute-specific satisfaction. Module B consisted of descriptions of negative critical incidents that the respondents were asked to judge. In module $\mathrm{C}$, respondents answered sociodemographic questions.

\section{Measures}

Satisfaction. Respondents rated their current satisfaction with the public transport service. Ratings were made of overall satisfaction (2 scales) and satisfaction with 13 attributes. The questions were intended to correspond to the following dimensions known to be important in public transport service (Friman and Gärling 2001) and other services (e.g., Edvardsson 1996): treatment by employees (how customers are treated by the staff and whether employees take appropriate actions), reliability of service (punctuality and travel time), straightforward information, and design (scales relating to comfort, security, and cleanliness). For each question, respondents checked a nine-point scale ranging from "very dissatisfied" to "very satisfied."

Frequency of Negative Critical Incidents. A set of 11 descriptions of negative critical incidents was presented in module $B$. These consisted of the negative critical incidents reported in Friman, Edvardsson, and Gärling (1998; 2001) based on analyses of actual experiences of public transport use obtained from customer complaints 
and interviews. The incidents referred to treatment by employees, reliability of service, simplicity of information, and design. In the questionnaire, one description was presented on each page.

Instructions explained that the descriptions referred to events that had happened to bus or streetcar passengers in the respondents' own region. Respondents were asked to read each description carefully and to indicate: (1) whether they had never, a few times, occasionally, or regularly experienced anything similar; (2) if they did not remember when it occurred, or if it was last week, last month, some time last year, or earlier; and (3) how negatively they experienced the incident.

\section{Results}

The 13 satisfaction scales were summed and averaged to yield four indices corresponding to treatment by employees, reliability of service, simplicity of information, and design (Friman, Edvardsson, and Gärling 2001). Table 2 reports means, SDs, Cronbach's alphas, and intercorrelations between the four indices among respondents of the total sample.

\section{Table 2. Intercorrelations, Cronbach's $\alpha \mathbf{s}^{\mathrm{a}}$, Means, and Standard Deviations of Index Variables}

\begin{tabular}{lccccccc} 
& & $M$ & SD & REL & TRE & SIM & DES \\
\hline Reliability of service & (REL) & 6.15 & 1.93 & $(0.82)$ & & & \\
Treatment by employees & (TRE) & 6.21 & 1.93 & 0.59 & $(0.91)$ & & \\
Simplicity in information & (SIM) & 6.01 & 1.81 & 0.59 & 0.55 & $(0.69)$ & \\
Design & (DES) & 6.45 & 1.76 & 0.54 & 0.53 & 0.58 & $(0.68)$ \\
\hline
\end{tabular}

${ }^{\mathrm{a} C} \mathrm{Cronbach}$ 's $\alpha$ s are given within parentheses in the main diagonal.

\section{Baseline Satisfaction}

A core aim of the improvements was to increase customer satisfaction in public transport. Figure 1 shows perceived satisfaction among the respondents in the pre-sample. The higher the score, the more satisfied with the specific dimension of the public transport service. 
Figure 1. Satisfaction in the Pre-Sample $(n=1048)$

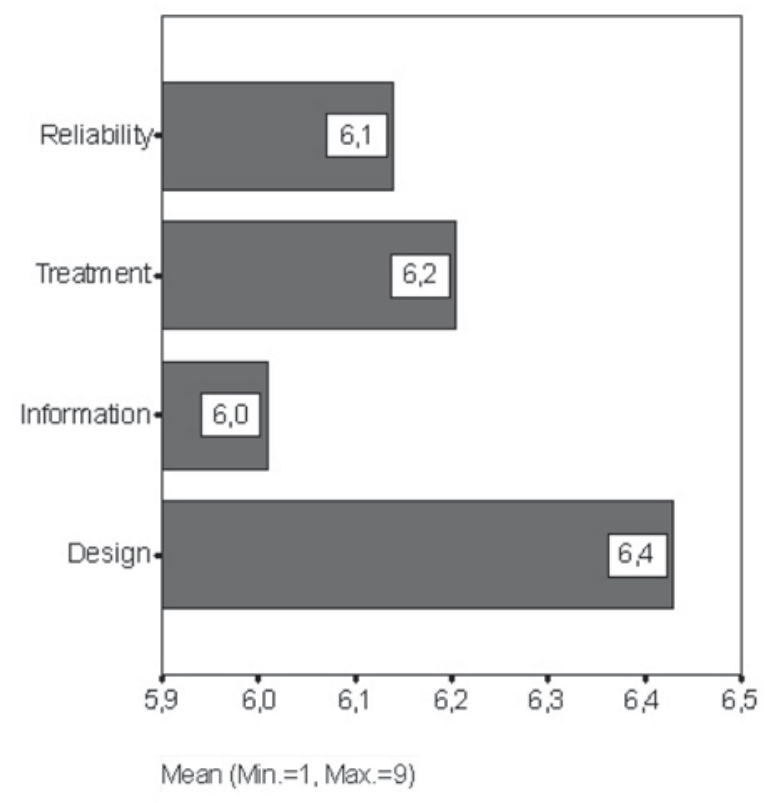

There were no gender differences in satisfaction $(p>0.01)$. However, significant differences in satisfaction were found when frequent users were compared with nonfrequent users. The former judged reliability of service lower than the latter ( mean $=5.7$ for frequent users and 6.2 for nonfrequent users, $t=5.4,<0.01$ ). They were also more dissatisfied with information (mean $=5.8$ for frequent users and 6.1 for nonfrequent users, $t=2.7,<0.01$ ), employee behavior ( mean $=5.8$ for frequent users and 6.2 for nonfrequent users, $t=4.4,<0.01$ ) and design ( $m e a n=6.0$ for frequent users and 6.5 for nonfrequent users, $t=4.9,<0.01$ ). There were no differences in satisfaction between those who had no or very few possibilities to choose other means of travel than bus ("captives") and those who had a choice $(p>0.01)$.

\section{Satisfaction Before and After Quality Improvements}

Mean ratings of the pre-test and post-test satisfaction measures in the different regions are summarized in Table 3. The results indicate that respondents in general rated the same levels of pre-test and post-test satisfaction independent of home region. 
Journal of Public Transportation, Vol. 7, No. 4, 2004

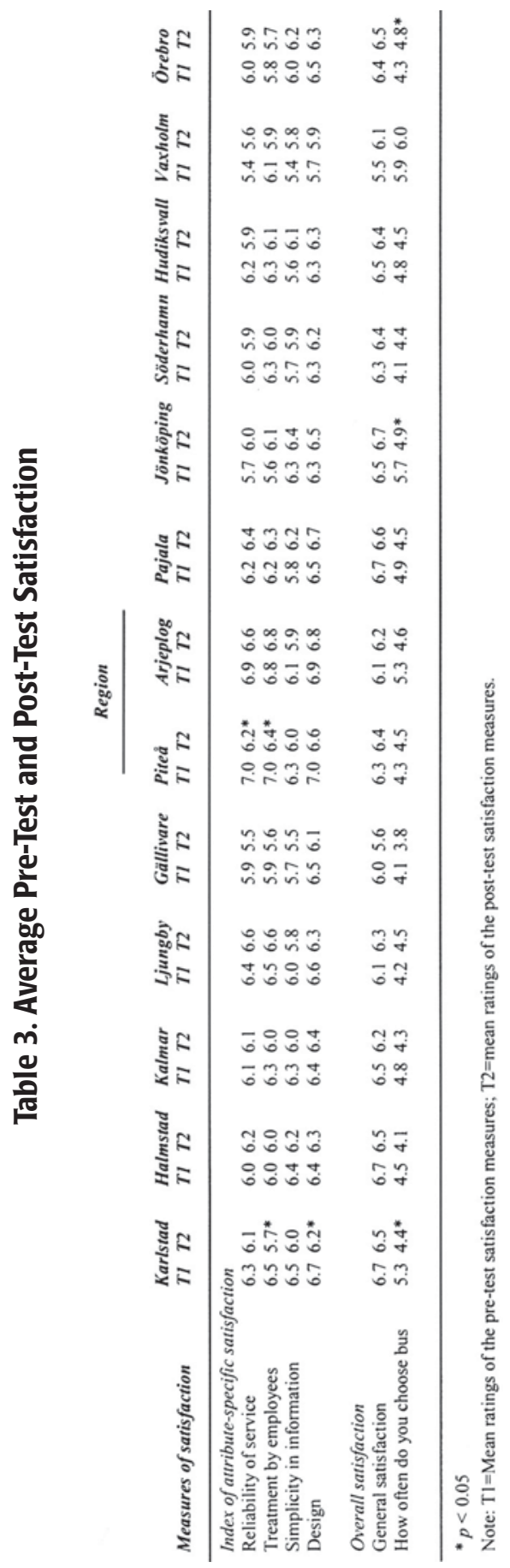

56 
Ratings of pre-test satisfaction were then compared with ratings of satisfaction following a specific quality improvement. The results displayed in Table 3 show that quality improvements, in general, do not generate higher satisfaction. In most cases, the respondents judged satisfaction to be lower or unchanged after the quality improvement.

Separate independent-samples $t$-test analyses at $p=0.05$ were then performed in each region. As shown in Table 3, only four differences were detected between pre-test and post-test attribute-specific satisfaction. All significant differences were in a negative direction, implying that respondents rated satisfaction lower after a quality improvement had been completed. In summary, the results did not confirm that satisfaction neither increases nor decreases when respondents are exposed to quality improvements in public transport services.

Independent $\mathrm{t}$-test analyses at $p=0.05$ showed that there were no significant differences between the pre- and post samples with regard to nonfrequent and frequent users. Satisfaction with quality improvements may vary according to trip purpose. However, a comparison between work, shopping, and leisure trips showed no significant differences between pre- and post-samples.

\section{Negative Critical Incidents Before and After Quality Improvements}

To investigate whether quality improvements lead to a change in the perceived frequency of negative critical incidents, means of the ratings were calculated for each type of negative critical incident in each region (see Table 4).

Pre-test ratings of frequency of negative critical incidents were then compared with the post-test ratings of frequency of negative critical incidents in each region. The results displayed in Table 4 indicate that quality improvements do generate some changes in perceived frequency of negative critical incidents. However, instead of decreasing the frequency, it seems as if improvements increase the frequency of perceived negative critical incidents.

Separate independent-samples t-test analyses at $p=0.05$ were then performed in each region. As seen in Table 4, some significant differences were detected between frequency of negative critical incidents before and after an improvement. Except in three cases, all significant differences were in a negative direction, implying that respondents perceived more negative critical incidents after a quality improvement. 


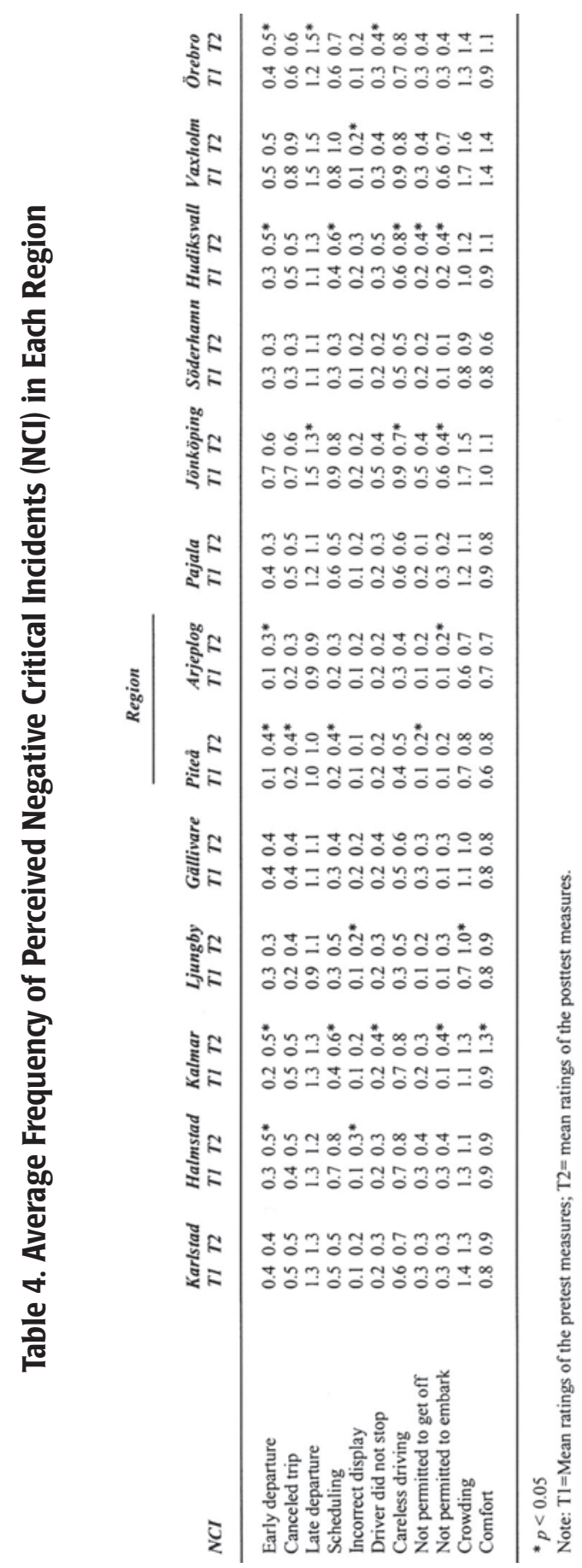


In summary, the results did not confirm that the frequency of negative critical incidents decreases when respondents are exposed to quality improvements in public transport services.

\section{Change in Satisfaction Related to Type of Improvement}

To investigate the relationship between type of improvement (better information systems, upgraded vehicle standard, increased number of departures, and new travel centers), satisfaction, and negative critical incidents, a comparison between the ratings of pre-test and post-test satisfaction and frequency of negative critical incidents were done within each type of quality project. In these comparisons, data from each region introducing the same quality improvement(s) were averaged. Table 5 shows the mean ratings of satisfaction and frequency of negative critical incidents for each type of quality development.

Table 5. Average Satisfaction and Frequency of Perceived NCIs Corresponding to Different Types of Quality Projects

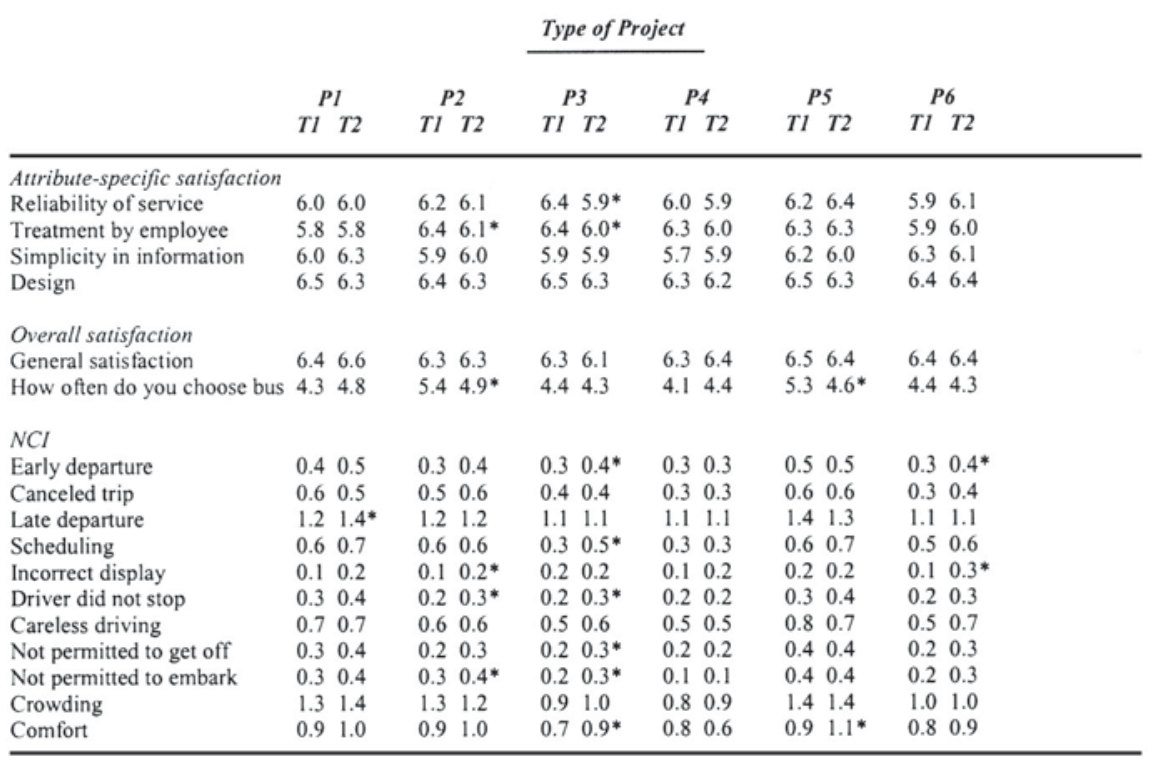

$* p<0.05$

Note: $\mathrm{P} 1=$ Improvements in information systems; $\mathrm{P} 2=$ improvements in vehicle standard; $\mathrm{P} 3=$ =xtended number of departures; $\mathrm{P} 4=$ information system and vehicle standard; $\mathrm{P} 5=$ information system and departures; $\mathrm{P} 6=$ vehicle standard and travel centers. $\mathrm{T} 1=$ pre-test, $\mathrm{T} 2=$ post-test. 
Separate independent-samples $t$-test analyses at $p=0.05$ were then performed for each type of project. Significant differences between pre- and post-test satisfaction were detected for quality projects involving upgrading of vehicle standard and more frequent departures. Again, post-test satisfaction was rated significantly lower after improvements. Respondents were then less satisfied with the reliability of the service and employee behavior. Better information systems and the construction of new travel centers did not cause any significant change in satisfaction.

Furthermore, changes in perceived frequency of negative critical incidents were reported in all projects, except one that included improvements in both information system and vehicle standard. Again, most significant changes were detected when the transport company increased the number of departures. Respondents rated a higher frequency of negative critical incidents relating to early departures, scheduling problems, lack of comfort, and rude treatment by employees (e.g., driver did not stop to permit passengers to embark or disembark). For all significant differences, the frequencies of negative critical incidents at Time 2 were rated higher than at Time 1.

In summary, the results indicated that improvements in information systems, vehicle standard, departures, and new travel centers do not improve satisfaction. On the contrary, the differences detected showed a decrease in satisfaction. Furthermore, improvements do not decrease respondents' perceptions of frequency of negative critical incidents. Differences detected show an increased frequency of critical incidents. The differences in satisfaction and critical incidents do not seem to be linked to any specific quality improvement. However, most changes were detected when transport companies increased the number of departures.

\section{Conclusions}

The main purpose of this study was to examine whether quality improvements in public transport have any effect on satisfaction and frequency of perceived negative critical incidents. An important finding is that the satisfaction people experience when using public transport services is influenced by quality improvements only to a limited extent, as shown in the difference between pre- and post satisfaction ratings.

Differences between reported satisfaction scales in the different time lags (Time 1 vs. Time 2) did not confirm previous research (e.g., Bolton and Drew 1991; Nilsson, 
Johnson, and Gustafsson 2001; Simester et al. 2000), showing that quality improvements raise customer satisfaction. In fact, the opposite came to light (in some cases significantly) in that the respondents reported less satisfaction after the implemented quality improvement. There are at least three possible explanations as to why the improvements did not boost passenger satisfaction.

First, frequent negative critical incidents stored in memory have been shown to affect satisfaction (Friman 2001). Quality improvements can be complicated by long implementation periods during which some service disruptions inevitably occur. Thus, when users of public transport services encountered quality improvements, they still reported an increase in frequencies of negative critical incidents, which resulted in lower levels of satisfaction. This is consistent with findings in previous research (Friman, Edvardsson, and Gärling 2001; Friman and Gärling 2001).

Second, negative critical incidents are perceived as situations where intended service performance fails to fulfill expectations. Knowledge of quality improvements may increase passengers' expectations, which will increase the number of reported negative critical incidents when the performance does not fulfill these expectations. Thus, it is suggested that expectations about a given service level determine whether passengers frequently perceive negative critical incidents.

Third, planning and operating departments in public transport companies may have difficulties cooperating and communicating. Careful central planning should be combined with a strategy that empowers employees to adapt and use these improvements to satisfy passengers.

Furthermore, results from this study suggest that disruptions affect perceptions and satisfaction ratings for some time. Yet another post-test would perhaps show stabilization in perceptions of negative critical incidents and an increase in satisfaction. Thus, it is not simple to identify improvements that will unequivocally boost passenger satisfaction.

Since it is important to understand what type of quality project can bring about changes in satisfaction and frequency of negative critical incidents, it is essential to compare passengers' reactions to different quality projects. Few differences between pre-test and post-test ratings were detected. However, a change in number of departures did induce lower ratings of satisfaction and more negative critical incidents than other quality projects. One explanation for this difference may be that such changes require a running-in period where punctuality may be affected. 
Punctuality is an important factor known to have a major impact on satisfaction and perceived service quality (Bradley et al. 1989; Prioni and Hensher 2000).

A possible explanation for the negative findings is that transportation planners and decision-makers have failed in the implementation phase. Thus, a question that future research could address is exactly how companies have implemented their improvements. Such studies could provide guidelines to the board of directors and top managers.

Although additional research is needed, a policy implication of the current research is that it highlights the important role of communication. Transportation planners and decision-makers should consider informing the public of intended quality programs. When the public is better informed about impending changes (and possible problems), expectations become more realistic. Decision-makers who plan to invest in quality in the future should prepare systematically to prevent an increasing number of negative critical incidents. A carefully designed and well-organized quality improvement could still be successful.

This study reported results of pre-test and post-test ratings in 13 regions in which transport companies have implemented quality improvements. The results did not confirm the basic premise that quality improvements automatically will increase passenger satisfaction. However, several limitations in this study should be acknowledged. For instance, the study contains data from regions where quality in public transport improvements have been accomplished. It would be optimal to compare this data with that from regions were no quality improvements have been made. Thus, the results may be influenced by other aspects than the implemented quality improvement. The strength of this study is, however, that it looks for trends regarding the impact of quality project emphases. It should also be noted that the time between implementation and post-test ratings might have been too short. 
Implementing Quality Improvements in Public Transport

\section{References}

Anderson, Eugene W., and Mary Sullivan. 1993. The antecedents and consequences of customer satisfaction for firms. Marketing Science 12: 125-143.

Bitner, Mary J., Bernard H. Booms, and Mary S. Tetreault. 1990. The service encounter: Diagnosing favorable and unfavorable incidents. Journal of Marketing 54: 71-84.

Bolton, Ruth N., and James H. Drew. 1991. A multistage model of consumers' assessments of service quality and value. Journal of Consumer Research 17: 375-384.

Bradley, M., E., S. Kroes, R. Widlert, Sheldon, T. Gärling, and S. Uhlin. 1989. Preferences for bus underground services in Stockholm. Paper presented at the 5th World Conference on Transport Research, July 10-14. Yokohama, Japan.

Cadotte, Ernest R., Robert B. Woodruff, and Roger L. Jenkins. 1987. Expectations and norms in models of consumer satisfaction. Journal of Marketing Research 24: $305-314$.

Churchill, Gilbert A., and Carol Surprenant. 1982. An investigation into the determinants of customer satisfaction. Journal of Marketing Research 14: 491-504.

Cronin, Joseph J., and Steven A. Taylor. 1992. Measuring service quality: A reexamination and extension. Journal of Marketing 58: 53-66.

Cunningham, Lawrence F., Clifford E. Young, and Errett J. Kroeter. 1995. Developing a customer focus in the statewide transportation planning process. Transportation Research Record 1499: 62-69.

Edvardsson, Bo. 1996. Tjänsteutveckling med inbyggd kvalitet [Service development with in-built quality]. Karlstad: Karlstad University Press.

Fornell, Claes. 1992. A national customer satisfaction barometer: The Swedish experience. Journal of Marketing 56: 6-21.

Friman, Margareta. 2001. The structure of affective reactions to critical incidents. Journal of Economic Psychology 25: 331-353.

Friman, Margareta, Bo Edvardsson, and Tommy Gärling. 1998. Perceived quality of public transport service: Inferences from complaints and negative critical incidents. Journal of Public Transportation 2: 69-91. 
Friman, Margareta, Bo Edvardsson, and Tommy Gärling. 2001. Frequency of negative critical incidents and satisfaction with public transport services. I. Journal of Retailing and Consumer Service 8: 95-104.

Friman, Margareta, and Tommy Gärling. 2001. Frequency of negative critical incidents and satisfaction with public transport services. II. Journal of Retailing and Consumer Services 8: 105-114.

Gotleib Jerry B., Dhruv Grewal, and Stephen W. Brown. 1994. Consumer satisfaction and perceived quality: Complementary or divergent constructs? Journal of Applied Psychology 79: 875-885.

leda, Hitoshi, Yoichi Kanayama, Masafumi Ota, Takashi Yamazaki, and Toshiyuki Okamura. 2000. How can the quality of rail services in Tokyo be further improved? Transport Policy 8: 97-106.

Nilsson, Lars, Michael D. Johnson, Anders Gustafsson. 2001. The impact of quality practices on customer satisfaction and business results: Product versus service organizations. Journal of Quality Management 6: 5-27.

Prioni, Paola, and David A. Hensher. 2000. Measuring service quality in scheduled bus services. Journal of Public Transportation 3: 51-74.

Oliver, Richard L. 1980. A cognitive model of the antecedents and consequences of satisfaction decisions. Journal of Marketing Research 17: 460-469.

Oliver, Richard L. 1997. Satisfaction. A behavioral perspective on the consumer. New York: McGraw-Hill.

Oliver, Richard L., and Wayne S. DeSarbo. 1988. Response determinants in satisfaction judgments. Journal of Consumer Research 14: 495-507.

Oliver, Richard L., and John E. Swan. 1989. Consumer perceptions of interpersonal equity and satisfaction in transactions: A field survey approach. Journal of Marketing 53: 21-35.

Simester, Duncan I., John R. Hauser, Birger Wernerfelt, and Roland T., Rust. 2000. Implementing quality improvements programs designed to enhance customer satisfaction: quasi-experiments in the United States and Spain. Journal of Marketing Research 37: 102-112.

Tse, David K., and Peter C. Wilton. 1988. Models of consumer satisfaction formation: An extension. Journal of Marketing Research 15: 204-212. 
Westbrook, Robert A. 1987. Product/consumption-based affective responses and postpurchase processes. Journal of Marketing Research 24: 258-270.

Westbrook, Robert A., and Richard L. Oliver. 1991. The dimensionality of consumption emotion patterns and consumer satisfaction. Journal of Consumer Research 18: 84-91.

\section{About the Author}

MARGARETA FrIMAN (margareta.friman@kau.se) holds a Ph.D. from the Department of Psychology at the University of Göteborg, Sweden. Her research interests deal with perceived service quality and customer satisfaction in public transport services. Dr. Friman is a senior lecturer in the Department of Psychology and a researcher at the Service Research Center, Karlstad University. 